\title{
HOW WILL WE CELEBRATE THE SECOND WILDLIFE CENTENNIAL?
}

\section{GEORGE F. LEDINGHAM, 2335 Athol Street, Regina, Saskatchewan. S4T 3G4}

Once, about 25 years ago, I was asked, "Why don't we ever see you at the Last Mountain Lake Sanctuary?" I explained that I had been there and I had seen the thousands of ducks, geese and cranes coming back to the lake at dusk. I had even on one occasion stayed overnight and was thrilled as cloud after cloud of wings rose into the presunrise prairie sky to go out to feed in the fields. The sights and sounds were unforgettable. The experience is most impressive when one is alone or sharing it with a few kindred souls. The area belongs to the birds and man must not intrude, at least he must not dominate in any way.

It is fitting that the Blue Jay, as the official publication of the Saskatchewan Natural History Society, should devote an issue to the 100th anniversary of the Last Mountain Lake Migratory Bird Sanctuary. For 45 years the Blue Jay, through its editors - Isabel Priestly, Clifford Shaw, Lloyd Carmichael and their successors and its contributors, has spoken for our natural heritage and tried to promote greater understanding and appreciation of it. This year hundreds of people, including many children, visited Last Mountain Lake to celebrate the culmination of 100 years of preservation and to renew our resolve to protect living creatures and to ensure them space to live out their lives.

This area has for thousands of years been a meeting and resting place for hundreds of thousands of birds. When the 77th annual meeting of the American Ornithologists' Union was held in Saskatchewan, a field trip was arranged to share what John A. Livingston describes as "one of the most spectacular natural events of the Canadian year." When James Fisher, the British ornithologist, watched the effortless wheeling of hundreds of Sandhill Cranes overhead, he said: "this alone was worth coming 4,500 miles to see." (Reports on the AOU meeting can be reread in the December 1959 issue of the Blue Jay.)

It is easy to look back at man's understanding and appreciation of nature. In this centennial year we should all review the problems of the past and help to plan for the second hundred years. In 1966, Lucy Murray wrote an article for the Blue Jay entitled "Bird sanctuaries in Saskatchewan 1887-1965" which is well worth reading. In 1930 there were 14 bird sanctuaries containing 476,038 acres $(66,156$ land, the rest water). In 1956 there were 15 sanctuaries but they covered only $38 \%$ of the water area and $6 \%$ of the land protected in 1930. Before 1930 there were 12 public shooting grounds but these were abolished in 1951 after pressure from agricultural interests. In 1930 the Natural Resources Transfer Agreement between the Federal Government and the Province of Saskatchewan was completed. By this agreement the province was not only to continue preserving bird sanctuaries and shooting grounds but to create additional ones.

Obviously, in Saskatchewan, sanctuaries have had their problems, the most recent being Redberry Lake. Not only were the sanctuaries open for hunting during legal shooting seasons in the early years, but the total needs of the birds have usually been poorly met since most sanctuaries include only water. This problem will persist as long as agriculture departments emphasize production per farmer rather than the value of good land and its 
long-term productivity. Farms are still getting larger and no land, no matter how marginal or how close to the water's edge, is safe from cultivation. Crop depredation is the term applied when birds or other wildlife feed on man's crops; the usual result of serious conflicts is that nature is brushed aside.

Other articles in this issue of Blue Jay describe the rededication of the Last Mountain Lake Bird Sanctuary, and various aspects of nature in the area. It was the abundance of birds which brought the area to the attention of Canada 100 years ago. Now the feeding and nesting needs of the birds are being considered and the future of the sanctuary is guaranteed for the next century. The articles make it clear that the area is important not just because of the water birds, but because of all the native plants and animals. Hopefully, ever-increasing numbers of people will be able to come to this sanctuary to gain a window into the lives of birds and other life forms. In this way the area can become an ever greater asset to man, but the activities of man in the area must be carefully controlled.

One cannot predict the future, but in the last 75 years the number of people on earth has increased nearly four times. This fact gives one cause to worry, but there are some hopeful signs. Man now recognizes that the resources of this earth, including space, are finite. It is also recognized that man shares this earth with other species and is dependent on them. Man will continue to use natural resources, but must use them in sustainable ways.

In June 1972 the United Nations organized its first global conference to examine the earth's environmental problems. Canadians presented briefs and sent a delegation to that conference in Sweden. Since then Canada has hosted a conference of environmentalists from around the world and has endorsed the
World Conservation Strategy. The three objectives of this Strategy are:

to maintain essential ecological processes;

to preserve genetic diversity including, wherever possible, the prevention of extinction of any species of plant or animal;

and thirdly, to ensure sustainable utilization of species and ecosystems.

Our governments, though frequently influenced by the urgency of winning an election, do try to think of the long-term good of the country and its people.

Governments, like humans, lack perfection and though the World Conservation Strategy was endorsed there has been little in the way of action towards meeting the objectives. The next 100 years may still be difficult for sanctuaries in Saskatchewan. All who have concerns for nature must resolve to work harder in the future. We have 100 years of experience to work from. We must cherish the gains made and work to preserve other habitats and ecosystems so that all species of plants and animals will have the chance for a future. The Whooping Crane was brought back from the very brink of extinction and the Last Mountain Lake Refuge is part of the habitat that is needed for its continued survival. Negotiations for an agreement which will protect some of our driest areas in a National Grasslands Park were not completed in the first 100 years; efforts toward that end cannot be relaxed while we search out other areas requiring preservation.

We cannot all be active in conservation but we can all support natural history societies (local, provincial and national) or wildlife, park, wilderness or other conservation groups. We can urge our friends to be interested in nature and supportive of its needs. Do you know areas which should be protected or which could 
possibly become an ecological reserve? Write to us about it. Help us to protect the Last Mountain Lake area and extend the same protection to other areas of remaining natural habitats.

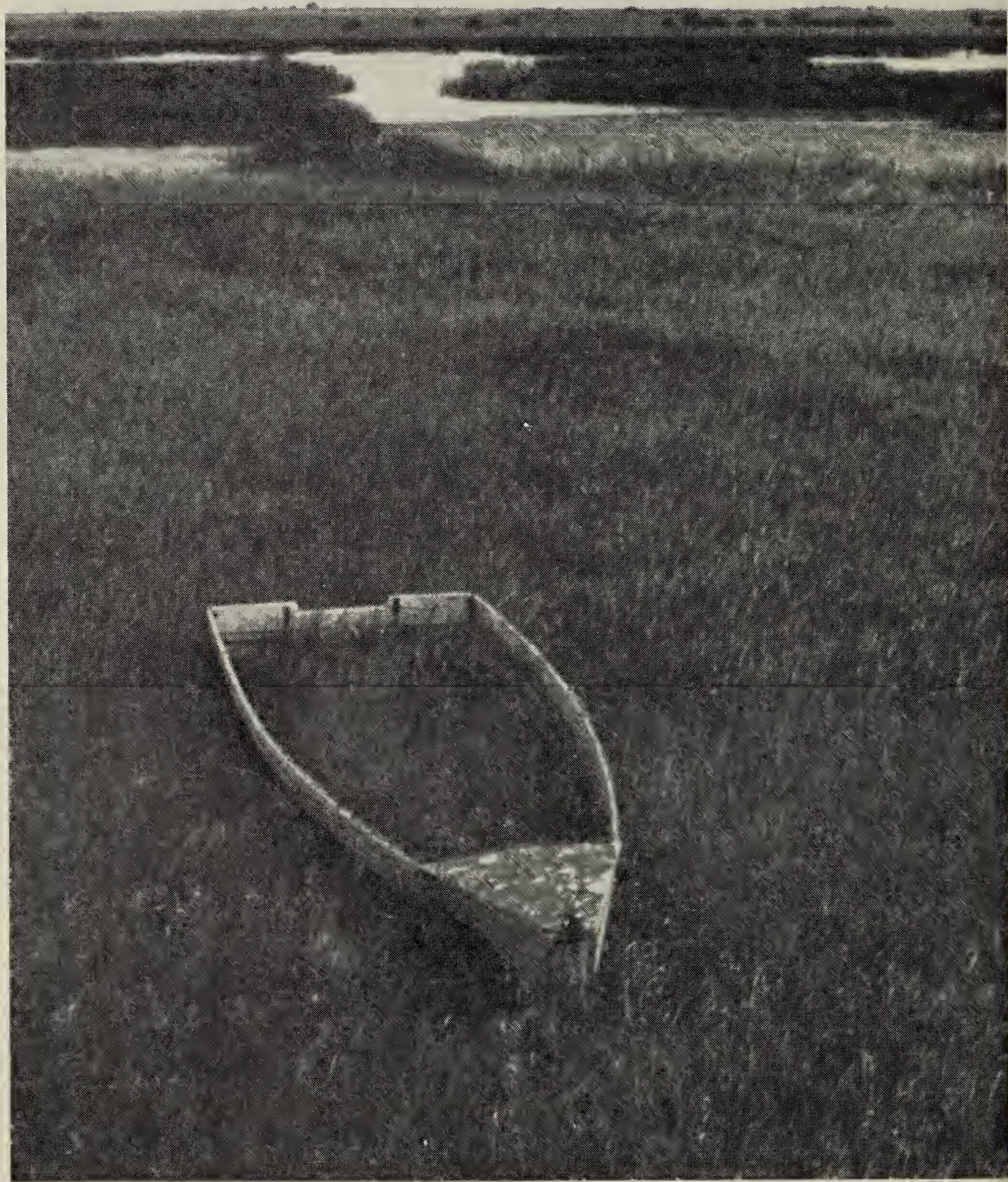




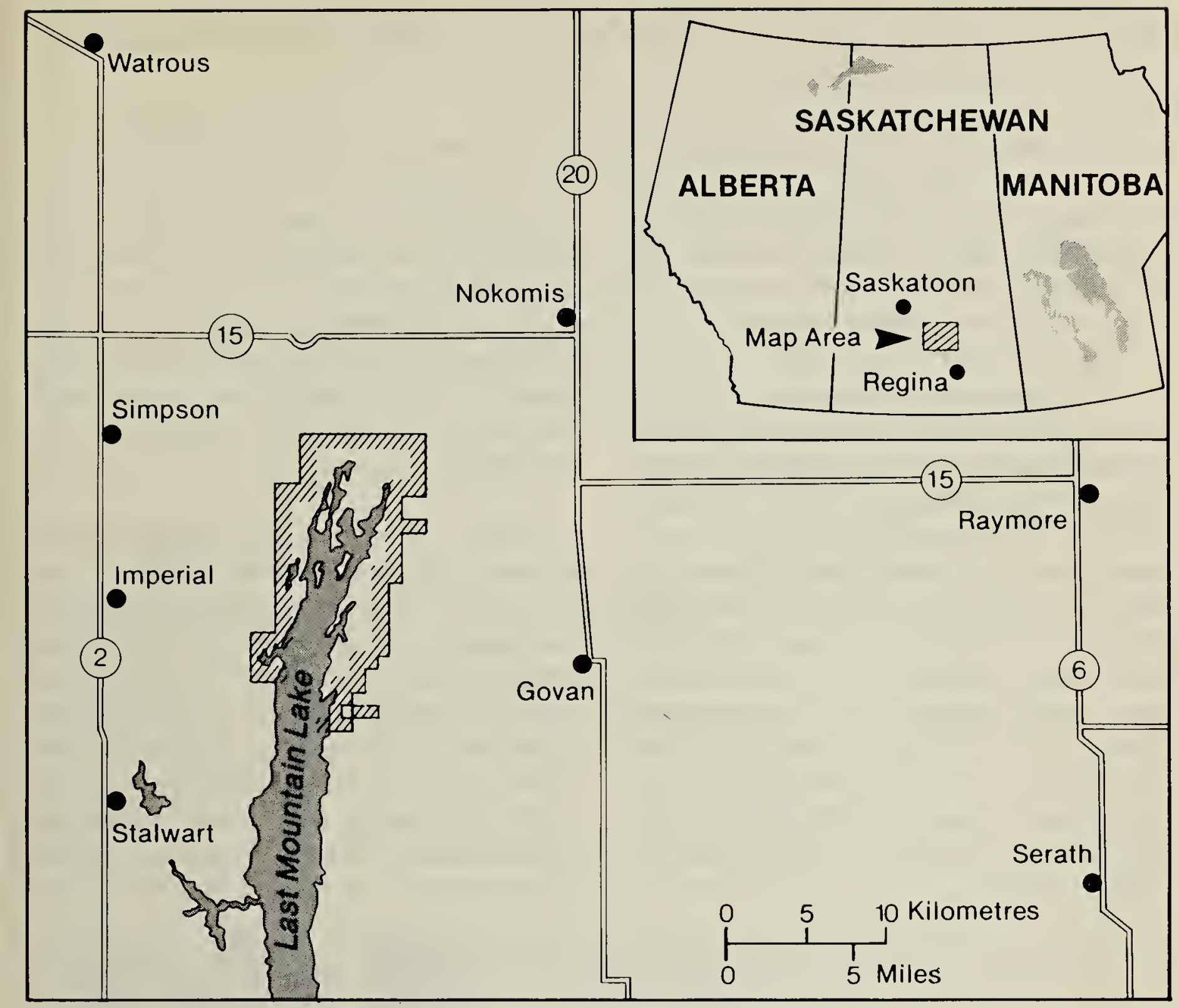

Last Mountain Lake National Wildlife Area, Saskatchewan

For further information and to report observations contact the following:

Area Manager

Canadian Wildlife Service

Box 280

Simpson, Sask.

SOG $4 \mathrm{MO}$ or

.

\section{Habitat Biologist} Canadian Wildlife Service 115 Perimeter Road Saskatoon, Sask. S7N 0X4 